\title{
HEALTHY GOVERNANCE AND HEALTHY PUBLIC POLICY: TOWARDS REALISTIC HEALTH REFORM AND EMPOWERED COMMUNITIES
}

\author{
David Briggs \\ Correspondence: dsbriggs007@gmail.com
}

The lead Editorial in this issue - a special issue, as it contains six articles presented at the College of Professional and Continuing Education (CPCE) of the Hong Kong Polytechnic University Health Conference of 2019 is provided by Professor Peter Yuen, Dean of that College and Professor, Department of Management and Marketing of the Hong Kong Polytechnic University.

The theme of the conference was 'Towards a More Humanistic, Holistic and Integrated Model of Care'. Invited speakers came from Japan, Korea, Singapore, Australia, China, Thailand, as well as locally from Hong Kong. You can see from the articles published that the various speakers brought a diversity of perspectives in their articles to the conference theme described above and brings into perspective this authors interest in the 'language of health reform'. As a plenary session speaker, I took the conference theme and thought carefully about its meeting and intent. The definitions of humanistic, holistic and integrated care are, of course variable dependent on the context. From my reading I concluded that the meaning pointed to 'patient centred care'. My professional context, these days is very much focussed on primary healthcare. [1] In addition, I have an abiding interest in health policy and health reform and the variable understanding we all have of the language of health reform.

At that time of the conference in Hong Kong, concern about health reform was contemporary as described in an earlier editorial. [2] Like many health systems there is now a focus on ageing with an under-pinning of prevention and an emphasis on primary healthcare. Part of that approach is the establishment of district health centres, community care and day care within an ageing care framework.
In my plenary presentation I made the point that Australia has had a lot of reform for health and the second point I made was that 'Australia had also had 'health reform without change and change without health reform'. This latter point created some level of humour in the audience response. However, despite that humour, the statement is in fact a truism. Calder and colleagues [3] recently published a report that concludes that Australian health services are too complex to navigate, and they traverse the multiple attempts at health reform over time to describe the inherent difficulties in effective reform. We also need to remember that the other challenge to health reform in Australia is the federated nature of government where there are split responsibilities for funding and delivering of healthcare predominately between State and Territory government and that of the Commonwealth Government.

Fran Baum in her recently published book on governing for health suggests six key measures that include 'reducing inequality to build population health, nesting human health in a broader ecosystem, good governance requires across sector involvement, regulation through public health, measurement of progress and ubiquitous leadership. John Menadue and colleagues have also recently contributed to the debate in Australia about Labor's proposed Australian Health Reform Commission just prior to a national election being called.[4]

Menadue suggests that we need 'an informed public discussion on health issues' and on 'how to improve our health system'. He goes on to suggest that 'providers have an effective veto on health reform'. I would suggest that the 'veto on health reform' goes much further than the interests of providers and goes also to multiple health professions, their industrial associations and professional 
organisations, health insurers and pharmaceutical and technology providers and the 'elephant in the room' of State and Territory governments and their extensive bureaucracies. After all, how many health ministries do you need for a mere 24 million people? This is at the nub of all the challenges we have in addressing Health reform in Australia. This is what is referred to as a 'strife of interests' as used by Sidney Sax as far back as 1985 [5] and more than adequately described by Alfords' 'structural interests' theory. [6] A perusal of the dates of the last two references demonstrates that the challenges we are all confronting are certainly not new.

Menadue suggests we need to address in priority order 'out of pocket costs', primary care, workforce reform, private health insurance, Medicare and the 'blame game', that is the 'structural interests, and the 'strife of interests. [5,6] I will not comment on his priorities or how he might have them addressed and like you all, we appreciate his ongoing contribution. The point this editorial make is that all the narrative above demonstrates strategic intent, an intent we have now been engaged in trying to address for the last four decades! Menadue goes on to add some principles such as 'a focus on users rather than providers', 'keeping people healthy (prevention)', solidarity and social inclusion, autonomy and choice and takes personal responsibility for keeping ourselves healthy'. [4]

In my mind the above words are representative of what we might call 'governing for health' and of developing 'healthy public policy'. [7] We have also talked, in the past, about the value of localism and the importance of theories around subsidiarity as away forward for health reform. [8] Returning to the conference theme of 'humanistic, holistic and integrated care and my definition of that meaning, 'patient centred care' I would now extend my definition to be underpinned by notions of 'community, interpersonal, social and individual care' [7] This is described by White as 'applying the socio-ecological model to health systems integration. [7] So this language suggests that we need to empower communities to be central to health decisionmaking at the individual and community level and not have healthcare as something 'we' do to individuals and communities.

In these contexts, why don't we pilot a move to placed based commissioning of groups of local government areas (LGAs) where consortiums of local hospitals, community health and PHC providers, together with citizens, bid to manage and deliver all local health services, to identify need and respond to that need and, inspire communities to achieve healthier lifestyles? The much larger Local Health Districts (LHDS) and PHNS would still have a role in connecting the smaller consortiums with referral to tertiary services, with establishing health and clinical pathways and supporting strategic planning and direction and overarching public health monitoring and regulation and supporting the retention of health workforce. Consideration of employment and industrial issues could be accommodated by retaining existing industrial rights through a process of secondment. The pilots would best work in rural communities and may not be effective in urban areas, but the need for health reform is a priority for rural communities that have poorer outcomes.

For those who say this cannot be done the response would be that it used to be the way health services were delivered in Australia before government and health bureaucracy 'slowly started to take control'. [9] A variant of this model was in place in NSW where rural district health services were established by a State government in 1993, only to be quickly disbanded by an incoming government who absorbed those local district health service into very large organisations within a few years of establishment. After four decades of not much progress in national health reform perhaps pilots at the local level that are empowering, innovative and entrepreneurial might just make some progress.

David Briggs

Note: The author is a board director of a current PHN

\section{References}

1. Briggs DS \& Nankervis, R. (2018) Australian Primary Health Networks: Innovation in Improving Patient Care. National Conference on District Health Systems Management Development towards SDGs Achievement. Phitsanulok Thailand. November 2018.

2. Briggs DS. (2018). Health Reform: What have we learned and where to next! APJHM13(3)

3. Calder, R. Dunkin, R. Rochford, C. Nichols, T. (2019). Australian Health Services: too complex to navigate: A review of the national reviews of Australia's health service arrangements. Australian Health Policy Collaboration Victoria University. Policy Issues Paper No. 1 - 2019. ISBN 0_6482621 - 3 - 8 
4. Menadue https://johnmenadue.com/john-

menadue-labors-proposed-australian-health-reform-

commission-is-a-welcome-start/

5. Sax Sidney. A Strife of interests: Politics and Policies

In Australian Health Services. 1984. George Allen \&

Unwin.

https://doi.org/10.1177\%2F144078338502100318.

6. Alford R (1975) Health Care Politics, The University of Chicago Press, Chicago.

7. White F. (2015) Primary Health Care and Public Health: Foundations of Universal Health Systems. Med Princ Pract 2015;24:103-116 DOI: 10.1159/000370197.

8. Briggs DS. (2014). Localism: A way forward? Asia Pacific Journal of Health Management 2014; 9: 1.

9. Crichton, A. 1990, Slowly Taking Control?

Australian Governments and Health Care

Provision 1788-1988, Allen \& Unwin, North Sydney. 